\title{
OBITUARY
}

\section{In memoriam: Mohamed Said Abdullah}

Professor Mohamed Said Abdullah, a pioneer of Kenyan and African nephrology, died on 28 May 2020 at the age of 76. A teacher, father and friend to many in the nephrology community, to me he was always Dr Abdullah, my mentor. He was married to my father's cousin, Shamsa, and on his visits to our home would inspire me with stories of his experiences in the hospital and with his patients. 'This is the man I want to be,' I told myself, 'I want to become a doctor.'

He was born in Malindi on II October 1943. He graduated with an MBChB degree from the prestigious Makerere University in Uganda in 1971, then studied internal medicine at the University of Nairobi. In 1975 he served as Chief Resident. From 1977 to 1978, Dr Abdullah pursued specialist training in nephrology at McGill University in Canada. He would always mention that he was one of the first students of Dimitrios Oreopoulos, a pioneer of peritoneal dialysis, during his training in Canada. After returning from McGill, Dr Abdullah lectured at the medical school of the University of Nairobi from 1978-1984. He was a consultant in nephrology at the Kenyatta National Hospital during this period and the chair of the Renal Unit until 1983, having established the unit in 1979 in the face of much administrative resistance. He joined Aga Khan Hospital in 1984 as a full-time private practitioner and served as chair of the department of medicine from 1978-1999.

Dr Abdullah was a founding member of the African Association of Nephrology and in 1990 became its president. By 1982, peritoneal dialysis had been established in Kenya. He was always proud of setting up the first successful peritoneal dialysis programme, at the Aga Khan Hospital, which would serve as a training ground for East and Central Africa. In 2011, he steered a task force on upscaling renal services in Kenya, which outlined
African Journal of Nephrology

Official publication of the African Association of Nephrology

Volume 23, No I, 2020, 128-129

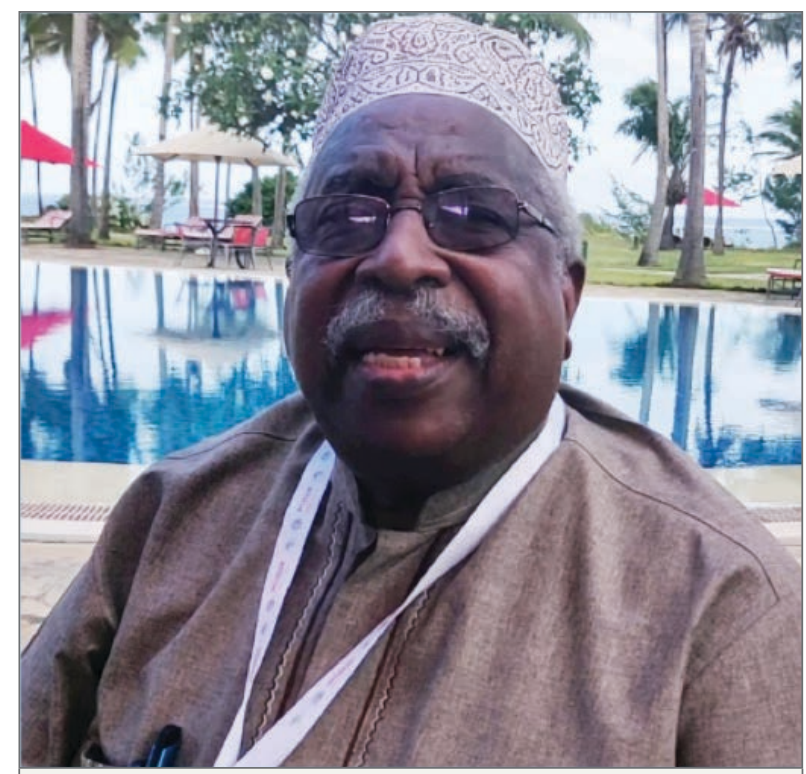

Mohamed Said Abdullah, 1943-2020.

a strategy of rolling out countrywide renal services, including haemodialysis centres in all the counties of the country. He was instrumental in setting up the haemodialysis unit at Tawfiq Hospital in Malindi, the city of his birth, and later supervised its operations.

Dr Abdullah was a teacher at heart. He spoke English eloquently and his command of Swahili was superb.

During my elective term at the Aga Khan Hospital, we saw a patient with diarrhoea. He ordered me to get a stool specimen, take it to the laboratory and look at the specimen under the microscope. I did exactly that, but I remember telling myself this was not what I signed up for! In 1995 I finished my postgraduate training in internal medicine, and he asked me to join him as his apprentice. In the three years that I worked for him, he taught me a great deal about medicine, and about life in general. I learnt how to deal with private patients, how to manage a private clinic, how to manage time effectively,

Received 02 June 2020; published 13 June 2020.

Correspondence: Ahmed Twahir, atwahir296@gmail.com. 
and much more. He supervised many dissertations of medical students and offered guidance to many about their career choices.

He was a strict disciplinarian as those who knew him well will tell you. During the ward rounds the nurses would be on top form. He was always the first one at work and would leave very late to go back home. He was dedicated to his work. However, he spent the weekends at home with his family.

He gave many guest lectures, presented at many local and international conferences and published extensively in peer-reviewed journals. He will be remembered as one of the longest-serving chairpersons of the Kenya Medical Research Institute (1984-2002). It was during his tenure that Kemron, an alpha interferon for the treatment of HIV/ AIDS, was developed and put Kenya on the world map for HIV research. During his long career, he also headed several other research institutions including the National Health Research and Development Centre (1990-200I) and the Global Council on Health Research for Development (1997-2004). He was also the chairman of the Kenya National AIDS Control Council (2000-2003).

From the Kenya Renal Association community, we say again: Inna lillahi wa inna ilayhi raji'un - Verily, from God we come and to Him we shall return.

\section{Ahmed Twahir \\ Kenya Renal Association}

